\title{
'Hannah's Choice' Highbush Blueberry
}

Mark K. Ehlenfeldt and Allan W. Stretch ${ }^{1}$

United States Department of Agriculture, Agricultural Research Service, Marucci Center for Blueberry and Cranberry Research and Extension, $125 \mathrm{~A}$ Lake Oswego Road, Chatsworth, NJ 08019

Nicholi Vorsa ${ }^{2}$

Rutgers University, Marucci Center for Blueberry and Cranberry Research and Extension, 125A Lake Oswego Road, Chatsworth, NJ 08019

\section{Arlen D. Draper ${ }^{3}$ \\ 604 East Park Drive, Payson, AZ 85541}

Additional index words. fruit breeding, Vaccinium corymbosum, Vaccinium atrococcum, tetraploid

Abstract. 'Hannah's Choice' is an early-ripening, tetraploid, highbush blueberry (Vaccinium corymbosum L.) that was developed by the cooperative breeding program of the Agricultural Research Service of the U.S. Department of Agriculture (USDA) and the New Jersey Agricultural Experiment Station (NJAES). It was named because it represents an improvement in sweetness, firmness, and flavor over currently grown early cultivars.

\section{Origin}

'Hannah's Choice', tested as G-805, originated from the cross G-136 $\times$ G-358 (Fig. 1). This cross was made by A.D. Draper at Beltsville, Md., in 1978. It is notable for having in its ancestry US 41, a 4x, colchicine-doubled clone of $V$. corymbosum forma atrococcum (Fig. 1). The original diploid clone was collected from the wild in New Jersey. V. corymbosum forma atrococcum germplasm is typically considered to be early ripening, and to have dark, sweet, soft fruit. 'Hannah's Choice' was selected in 1982 from a seedling-field grown at the Atlantic Blueberry Co., Hammonton, N.J., by A.D. Draper. It was subsequently evaluated by A.D. Draper, G.J. Galletta, G. Jelenkovic, N. Vorsa, A.W. Stretch, and M.K. Ehlenfeldt at Atlantic Blueberry Co. and Variety Farms, in Hammonton, N.J. These workers continued the evaluation of 'Hannah's Choice' from 1984 through 1998 in test rows of vegetatively propagated clones at the Atlantic Blueberry Co., and finally in a replicated planting of elite clones and standard cultivars at Variety Farms, Hammonton, consisting of four replicates of five plants, each in a randomized complete block design, from 1996 to 2001. Both the Atlantic Blueberry Co. and the Variety Farms trials were located on farms in USDA Plant Hardiness Zone 6, on soils that are mostly Atsion sand containing $3 \%$ to $15 \%$ organic matter. Cultural practices at Atlantic Blueberry Co. included the use of solid set irrigation for irrigation and frost protection. The yield trial plots at Variety Farms used similar practices with the addition of incorporating peat to the planting holes and mulching with pine bark. Testing of 'Hannah's Choice' was also conducted in Michigan, Arkansas, Oregon,

Received for publication 13 Dec. 2004. Accepted for publication 23 Jan. 2005. and North Carolina. 'Hannah's Choice' was released in 2000 .

\section{Description}

Evaluation of the original 'Hannah's Choice' plant and of subsequently propagated plants established in a replicated trial at Hammonton during 1993-98 indicated that the most impressive traits of 'Hannah's Choice' are early ripening, medium- to large-sized fruit, excellent firmness, high levels of soluble solids, and excellent flavor with pleasant peach overtones. Numerical rating data collected between 1985 and 1993 on the original plant and clonally propagated plants showed that 'Hannah's Choice' fruit as compared to 'Duke' fruit, rated-higher for flavor, slightly higher for size, color, firmness, and equivalent for scar (data not shown). Adetailed comparison of fruit characteristics of 'Hannah's Choice' relative to 'Chanticleer' (Ehlenfeldt et al., 2000), 'Weymouth' (Coville, 1937), and 'Duke' (Draper et al., 1987) from yield plots in 1996-2001 (Table 1) also shows 'Hannah's Choice' to be superior to the other cultivars in size, firmness, and soluble solids. Its fruit are medium to light blue, with good scars, and excellent firmness.

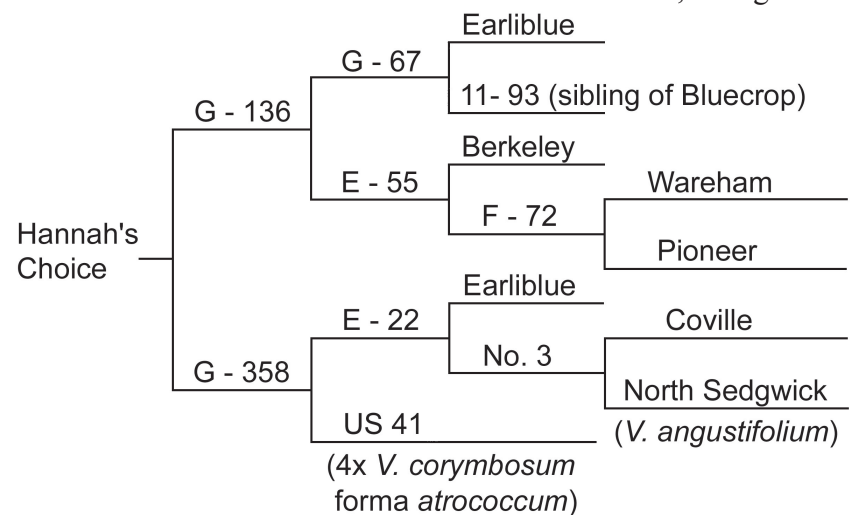

Fig. 1. Pedigree of 'Hannah's Choice' highbush blueberry. Fruit size is somewhat variable, with earlier developing fruit being larger, and decreasing in size through progressive harvests. Across 8 years (1996-2001) fruit size ranged from $1.9 \mathrm{~g}$ at first harvest to $1.6 \mathrm{~g}$ at third harvest. Some fruit is smaller still, and later to develop, and probably would not be commercially harvested (Fig. 2) The cause of this small

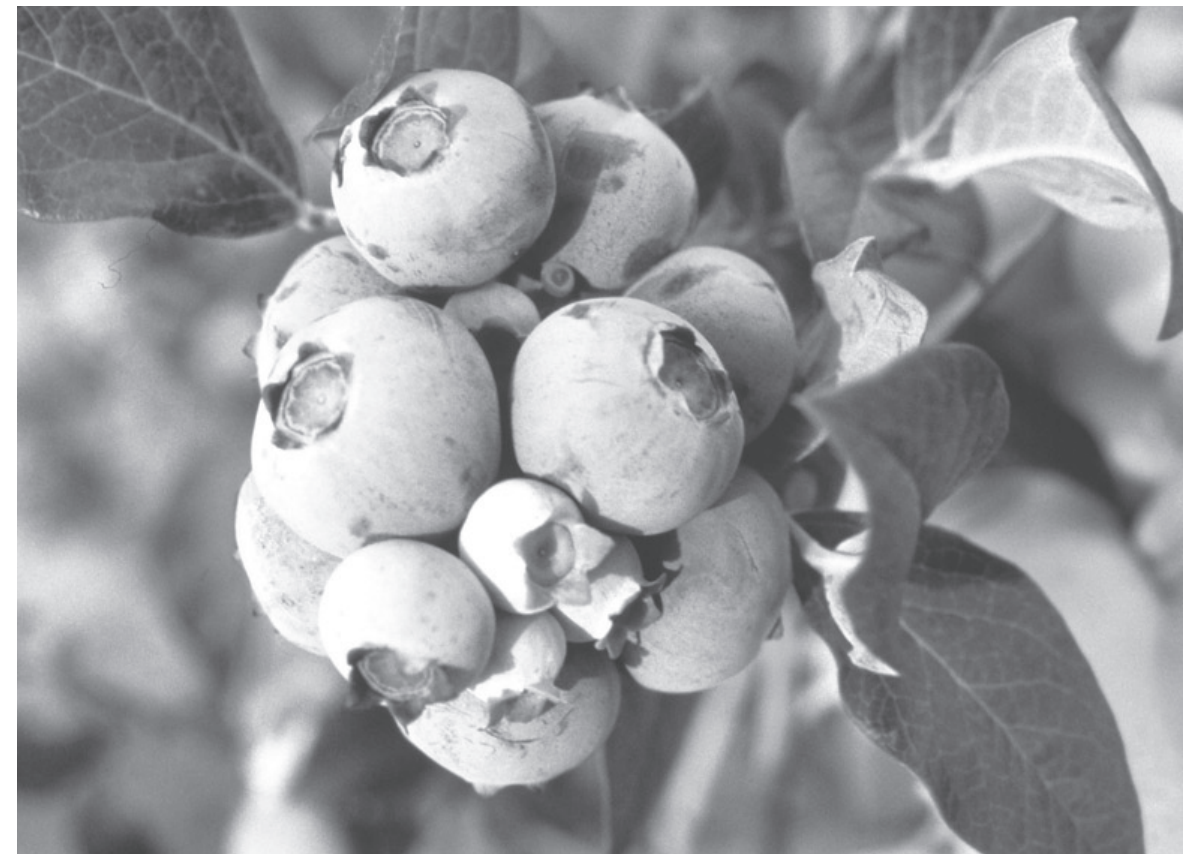

Fig. 2. 'Hannah’s Choice’ highbush blueberries. 
Table 1. Fruit weight, color, firmness, soluble solids, titratable acidity, estimated 50\% ripening dates, and representative yields for 'Weymouth', 'Duke', 'Bluecrop', 'Chanticleer', and 'Hannah's Choice' summarized across all harvests at Variety Farms in Hammonton, New Jersey in 1996 through 2001. Plants were set in the field in 1993.

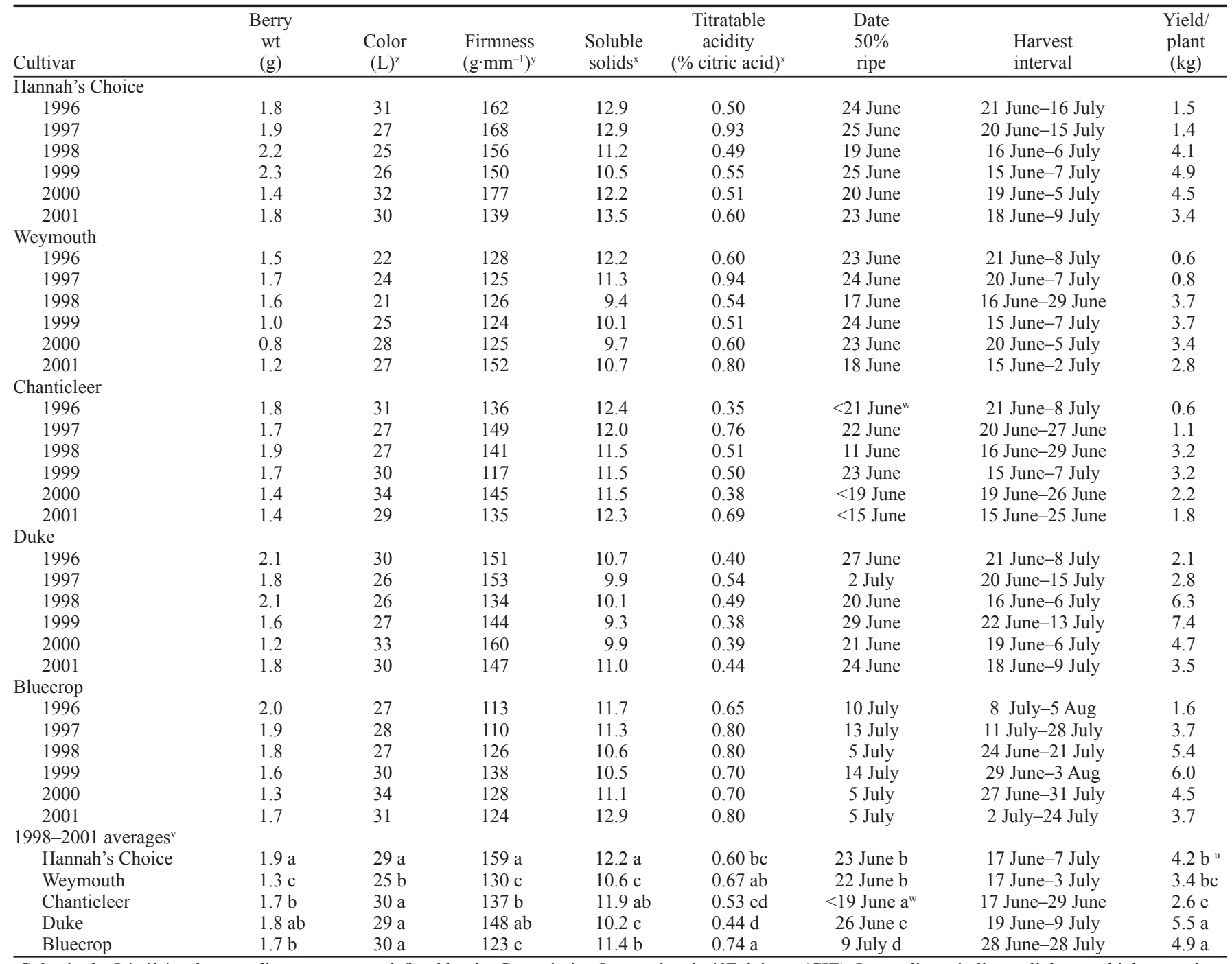

${ }^{2}$ Color in the $\mathrm{L}^{*} \mathrm{a} * \mathrm{~b} *$ color coordinate system as defined by the Commission Internationale 1'Eclairage (CIE). L coordinate indicates lightness; higher numbers indicate lighter color. Color meter aperture, $50 \mathrm{~mm}$.

${ }^{y}$ Grams of force needed to produce $1 \mathrm{~mm}$ of deflection, averaged across 30 intact fruit.

${ }^{x}$ Soluble solids and titratable acidity were determined on a blended one cup sample of fruit.

wIn some years, 'Chanticleer' was $>50 \%$ ripe at first harvest. In these years, the day previous to first harvest was used for statistical calculations as the day of $50 \%$ ripeness. Thus the $50 \%$ ripe estimate for 'Chanticleer' represents a conservative estimate of $50 \%$ ripeness date.

${ }^{v}$ Analysis of variance performed using the SAS GLM procedure (SAS Institute, Cary, N.C.). Means within columns with different letters are significant at the 0.05 level.

"Yield averages represent yield across 1998-2001, when plants had reached mature stature.

fruit has not been studied. Fruit is sweet, subacid, and mild-flavored with pronounced peach accents. The high levels of soluble solids in 'Hannah's Choice' represents an about 20\% relative increase in soluble solids over the average values for 'Duke', and its firmness represents an approximate $7 \%$ relative increase over 'Duke'. The estimated date for $50 \%$ ripe fruit ranged from 19 to 25 June, and averaged 23 June. This is $1 \mathrm{~d}$ later than the same ripeness for 'Weymouth', but $3 \mathrm{~d}$ earlier than the same ripeness for 'Duke'. Production in New Jersey on mature plants in mixed plantings has been about $75 \%$ of 'Duke'(Table 1 ). In limited postharvest storage studies, 'Hannah's Choice' has stored better than 'Weymouth', 'Chanticleer', or 'Bluecrop' (Draper and Hancock, 1990) under a range of storage regimes and has had consistently higher percentages of sound fruit after one week of storage than these cultivars. It has stored slightly less-well than 'Duke' (data not shown).

'Hannah's Choice' is an upright bush, with pink-tinged flowers. It flowers as early, or earlier than 'Weymouth'. Although it may be susceptible to damage from late frosts, it has seldom suffered serious damage, and may have some innate level of cold tolerance. Mature leaves have distinctly waved margins and a slightly twisted midrib. Observations of percent flowering during the first week of May at Hammonton, NJ in 1995-97 showed 'Hannah's Choice' and 'Weymouth' flower early, and reach their peak flowering at roughly equivalent times, whereas cultivars such as 'Chanticleer', 'Duke', and 'Bluecrop' reach their peaks slightly later. Studies in New Jersey have shown that 'Hannah's Choice' is relatively susceptible to mummy berry blight caused by the fungus Monilinia vaccinii-corymbosi Reade (Honey), and has average resistance to the secondary, fruit-infection stage (unpublished data). Recent studies of anthracnose fruit-rot resistance have shown it to be in the top $25 \%$ of 100 cultivars tested, and to have better resistance than 'Duke' (Polashock, et al. 2005) 'Hannah's Choice' has been a consistently good performer in New Jersey producing reliable yields, but has been more variable in other regions, producing low to moderate yields in Michigan (Grand Junction), Arkansas (Clarksville), Oregon (North Willamette), and North Carolina (Castle Hayne). 'Hannah's Choice' is recommended as an early season cultivar primarily for commercial growers in northeastern temperate regions, including New Jersey and adjoining states. 


\section{Availability}

Plants of 'Hannah's Choice' have been distributed to commercial propagators; neither the USDA nor NJAES currently has plants for distribution. Growers may request information on how to obtain propagules by contacting M. K. Ehlenfeldt, USDA-ARS, Marucci Center for Blueberry and Cranberry Research and Extension, 125A Lake Oswego
Road, Chatsworth, NJ 08019. Genetic material of this release has been deposited in the National Plant Germplasm System where it will be available for research purposes.

\section{Literature Cited}

Coville, F.A. 1937. Improving the Wild Blueberry, p. 559-574. In: Yearbook of agriculture. U.S. Dept. Agr., Wash., D.C.

Draper, A. and J. Hancock. 1990. The 'Bluecrop' highbush blueberry. Fruit Var. J. 44:2-3.

Draper, A., G. Galletta, G. Jelenkovic, and N. Vorsa. 1987. 'Duke' highbush blueberry. HortScience 22:320.

Ehlenfeldt, M.K., N. Vorsa, and A.D. Draper. 2000. 'Chanticleer' highbush blueberry. HortScience 35:780-782.

Polashock, J.J., M.K. Ehlenfeldt, A.W. Stretch, and M. Kramer. 2005. Anthracnose fruit-rot resistance in blueberry cultivars. Plant Dis. 89:33-38. 